\title{
Produção e compreensão de textos em uma perspectiva de desenvolvimento
}

\author{
Ana Carolina Perusi Brandão \\ Alina Galvão Spinillo \\ Universidade Federal de Pernambuco
}

\begin{abstract}
Resumo
Tradicionalmente investigadas separadamente, a produção e a compreensão de textos são, neste estudo, examinadas de forma conjunta, investigando-se as relações entre tais habilidades em uma mesma amostra de participantes. Sessenta crianças de 4, 6 e 8 anos foram solicitadas a elaborar oralmente uma história a partir de um tema dado (tarefa de produção), e a reproduzir uma história ouvida em gravador (tarefa de compreensão) que versava sobre o mesmo tema apresentado na tarefa de produção. Apesar de ambas as habilidades se desenvolverem com a idade, não detectou-se uma correlação entre produção e compreensão de textos. Aos 4 anos, as crianças apresentavam níveis de produção mais elaborados do que na compreensão; enquanto aos 6 e 8 anos apresentavam níveis de compreensão mais elaborados do que na produção. Os resultados são interpretados em uma perspectiva de desenvolvimento, discutindo-se as diferentes formas de lidar com textos que servem de modelo para a reprodução.
\end{abstract}

Palavras-chave: Produção e compreensão de textos, Desenvolvimento, Crianças.

\begin{abstract}
Text production and text comprehension on a developmental approach Text production and text comprehension are usually investigated separately. In this study both abilities are taken in conjunction in order to explore the relationships between them. Sixty 4, 6 and 8-year-old children were asked to produce orally a story about a given topic (production task). They were also asked to retell a story they listened in a tape recorder (comprehension task) which was about the same topic presented in the production task. Though both abilities developed with age, no correlation was found between text production and text comprehension. At the age of 4 years, children were more successful in the production task than in the comprehension task; whereas at the ages of 6 and 8 years children did better in the comprehension task than in the production task. These results are interpreted in a developmental approach. The different ways in which children deal with texts are discussed.
\end{abstract}

Key words: Text production and text comprehension, Development, Children

$\mathrm{C}$ onsideradas habilidades lingüísticas e cognitivas da maior importância, a compreensão e a produção de textos são temas que há muito interessam pesquisadores e teóricos da psicologia do desenvolvimento. Estas habilidades são usualmente investigadas separadamente, sendo raras as pesquisas que examinam as possíveis relações entre produzir e compreender textos em uma mesma amostra de participantes.

Como recentemente discutido por Brandão e Spinillo (1998), as pesquisas que investigam a compreensão de textos caracterizam-se pelo uso de dois tipos de recursos metodológicos: (a) reprodução (oral ou escrita) de um texto apresentado (lido, ouvido, acompanhado ou não de gravuras); e (b) respostas a perguntas sobre um texto lido/ouvido pela criança. Poucas são as pesquisas que combinam ambas as metodologias em uma mesma amostra, como é o caso de estudo realizado por Marcuschi (1989) com adultos e adolescentes; e o estudo de Brandão e Spinillo (1998) com crianças pré-escolares e em séries iniciais do ensino fundamental. Na realidade, a grande maioria dos estudos sobre compreensão de textos adota a segunda alternativa, procurando examinar os fatores responsáveis pela compreensão de tex- 
tos, tais como: fatores lingüísticos (sintáticos, semânticos, léxicos, habilidade de decodificação); e fatores cognitivos (memória de trabalho, capacidade de monitoramento, inferências e capacidade de integrar as informações veiculadas no texto). De modo geral, o interesse dos pesquisadores reside em determinar o nível de contribuição de cada um desses fatores no processo de compreensão e procuram esclarecer as causas das dificuldades experimentadas por crianças ao compreender textos (e.g., Perfetti, Marron \& Foltz, 1996; Oakhill \&Yuill, 1996; Yuill \& Oakhill, 1991).

No que concerne à produção, o procedimento metodológico sistematicamente adotado nas pesquisas consiste em solicitar a produção (oral ou escrita) de um texto, a partir de gravuras, de filmes ou de um tema dado. O interesse recai sobre como ocorre o desenvolvimento na aquisição da estrutura narrativa por parte do produtor do texto. Estes estudos mostram que a habilidade de produzir textos se desenvolve desde muito cedo e que as principais dificuldades das crianças residem na elaboração de uma situação problema e na criação de um desfecho que esteja em estreita relação com os eventos anteriormente narrados (e.g., Bernan \& Slobim, 1994; Hudson \& Shapiro, 1991; Rego, 1986; Shapiro \& Hudson, 1997; Spinillo, 1996; Spinillo \& Martins, 1997; Spinillo \& Pinto, 1994).

Considerando as diferentes formas de avaliar as habilidades de compreensão e de produção de textos, como, então, têm procedido os pesquisadores ao examinar ambas as habilidades conjuntamente? Quais os resultados encontrados? Tais habilidades se correlacionam ou são independentes? Em relação aos resultados obtidos, estes estudos apontam resultados contrastantes, como discutido a seguir.

\section{As relações entre compreensão e produção de textos}

Pesquisas que investigam as relações entre compreensão e produção de textos, como mencionado, são raras. Algumas delas avaliam a compreensão através de perguntas sobre determinado texto e a produção através da elaboração de um texto. Outras, entretanto, adotam tarefas em que a produção é avaliada através da elaboração de um texto e a compreensão através da reprodução de um texto ouvido/lido, de forma que o produto final a ser analisado em ambas as tarefas é um texto. Considerando esses dois grupos de pesquisas, discute-se, a seguir, estudos que examinam as relações entre produção e compreensão de textos em crianças e os resultados neles obtidos.

Cain e Oakhill (1996) investigaram a natureza das relações entre compreensão e produção de histórias em crianças de 7-8 anos de idade. As crianças foram divididas em três grupos: Grupo 1 - nível de compreensão abaixo do esperado naquela idade; Grupo 2 - nível de compreensão aci- ma do esperado naquela idade, e Grupo 3 - nível de compreensão compatível com a idade, servindo, este grupo, como parâmetro de comparação para os outros dois. O nível de compreensão foi avaliado através de um teste padronizado que consiste, basicamente, em responder perguntas sobre pequenos textos lidos, cuja complexidade aumenta no decorrer do teste. A produção foi avaliada através da elaboração oral de histórias em duas condições: a partir de um tema fornecido pelo examinador, e a partir de uma seqüência de gravuras. As histórias foram categorizadas em: não-história, história incompleta e história completa.

A predição era que os menos habilidosos em compreensão (Grupo 1) produziriam histórias mais elementares do que as crianças do Grupo 3 (compreensão compatível com a idade); enquanto as crianças mais habilidosas (Grupo 2) produziriam histórias mais sofisticadas do que as crianças dos outros dois grupos. Em outras palavras, a hipótese era que a qualidade da história produzida estaria relacionada à habilidade de compreensão.

No geral, as histórias eram mais elaboradas quando produzidas a partir da sequiência de gravuras do que a partir do tema; sendo este efeito mais acentuado entre as crianças menos habilidosas em compreensão (Grupo 1) para as quais as gravuras auxiliavam a produção. Observou-se, ainda, que os outros dois grupos eram sistematicamente melhores nas produções do que as crianças com nível elementar de compreensão. Este resultado indica uma correlação entre produção e compreensão: crianças com um bom nível de compreensão também são boas produtoras de textos; enquanto crianças com dificuldades de compreensão produzem histórias elementares (incompletas ou não-histórias), principalmente quando não existem referentes, como as gravuras, que sugerem a estrutura de uma história.

Adotando uma tarefa de reprodução para avaliar a compreensão de textos de crianças de 4 e 5 anos, Guttman e Frederiksen (1985), examinaram as relações entre as habilidades de produção e compreensão de histórias. Na tarefa de produção, solicitava-se das crianças a elaboração de uma história a partir de um livro com uma sequiência de gravuras e a partir de uma única gravura com três personagens, os quais eram os mesmos presentes na seqüência de gravuras. As produções foram analisadas com base na estrutura clausal, na estrutura proposicional e na densidade proposicional das sentenças.

Na tarefa de compreensão, as crianças ouviam uma história em gravador, enquanto olhavam um livro com ilustrações correspondentes ao texto que estava sendo ouvido, texto este diferente daquele apresentado na tarefa de produção. Em seguida, eram solicitadas a recontar a história, utilizando as ilustrações do livro como apoio. A compreensão foi avaliada em termos da porcentagem de proposições relem- 
bradas ou nas quais as inferências se baseavam. Dois níveis de compreensão foram identificados - superior e inferior, definidos em termos do escore mediano alcançado pela amostra como um todo. Estes níveis foram adotados para investigar as relações entre compreensão e produção quanto a cada aspecto considerado (estrutura clausal, estrutura proposicional e densidade proposicional).

Os resultados mostraram que as reproduções apresentavam uma densidade proposicional maior do que as histórias produzidas, e que isto ocorria em relação às crianças classificadas no nível superior e no nível inferior de compreensão. As produções das crianças com um bom nível de compreensão eram semelhantes às produções das crianças com um nível elementar de compreensão; não havendo, portanto, uma correlação entre a qualidade da história produzida e o nível de compreensão dos participantes. A única correlação significativa verificada entre produção e compreensão ocorreu quanto à densidade proposicional, visto que, as crianças com boa compreensão eram aquelas que produziam histórias com um grande número de proposições.

Importante comentar que neste estudo a forma como a reprodução foi analisada enfatizava a capacidade de relembrar proposições do texto original, sem atentar para a reprodução das idéias principais contidas no texto original e sem considerar os aspectos relativos à organização textual da história reproduzida. Em outras palavras, negligenciouse a estrutura do texto reproduzido e privilegiou-se a fidelidade às proposições do texto original. Como apresentado adiante, a presente investigação adota forma distinta de análise da reprodução de textos.

Nas investigações acima descritas o planejamento experimental consistia em dividir as crianças em função do nível de compreensão que apresentavam. Após esta divisão, era avaliada a habilidade de produção, examinando se os bons compreendedores seriam, também, bons produtores, e se maus compreendedores seriam, também, maus produtores de textos. Os resultados obtidos nesses estudos divergem quanto às relações entre estas habilidades. Enquanto Guttman e Frederiksen (1985) não encontram correlação entre produção e compreensão, Cain e Oakhill (1996) verificaram que crianças com dificuldades de compreensão apresentam uma produção elementar. Uma possível explicação para esta divergência pode estar relacionada às idades investigadas. No estudo conduzido por Cain e Oakhill, as crianças tinham 7-8 anos de idade, e no estudo de Guttman e Frederiksen, as crianças eram bem mais jovens, com idades entre 4-5 anos. Considerando-se os grupos etários nesses estudos como um todo, é possível perguntar se a divergência entre os resultados não seria decorrente do desenvolvimento: inicialmente as habilidades de produção e de compreensão não se correlacionariam (4-5 anos), como aponta- do por Guttman e Frederiksen; porém, com o aumento da idade, existiria uma correlação entre produzir e compreender textos (7-8 anos), como indicado por Cain e Oakhill. Esta é uma questão importante que será investigada no presente estudo.

\section{Objetivos, hipótese e proposta de análise do estudo}

A presente investigação tem por objetivo examinar as relações entre produção e compreensão de textos. Considerando a divergência entre os resultados obtidos nos estudos mencionados é possível supor que, inicialmente, essas habilidades não se correlacionam e que, posteriormente, ao longo do desenvolvimento, esta correlação passa a existir. Esta possibilidade explicaria, então, as discordâncias encontradas entre os resultados daqueles estudos. Esta hipótese é examinada em uma perspectiva de desenvolvimento, explorando-se as relações entre produção e compreensão de textos: (a) em diferentes faixas etárias; (b) analisando-se a produção em relação à estrutura lingüística textual, organização da cadeia narrativa e estabelecimento de relações dentro do texto; (c) avaliando-se a reprodução, considerando, simultaneamente, os aspectos relativos à produção de um texto (estrutura, cadeia narrativa, estabelecimento de relações dentro do texto) e a relação da reprodução com o texto original quanto à fidelidade das idéias contidas no texto, e não em termos de proposições como o fizeram Guttman e Frederiksen. Entende-se que a atividade de reproduzir textos envolve a produção de um novo texto, porém não de qualquer texto; mas um que veicule os principais blocos de informação presentes no texto original.

As relações entre compreensão e produção de textos serão, portanto, examinadas a partir dos três pontos acima citados em uma perspectiva de desenvolvimento.

\section{Método}

\section{Participantes}

Sessenta crianças, de ambos os sexos, de classe média, alunas de uma mesma escola particular da cidade do Recife, foram igualmente divididas em três grupos etários: 4 anos (média: 4 anos e 6 meses; 12 do sexo feminino e 8 do sexo masculino), 6 anos (média: 6 anos e 6 meses; 10 crianças de cada sexo) e 8 anos (média: 8 anos e 4 meses; 11 do sexo feminino e 9 do sexo masculino).

\section{Procedimento e planejamento experimental}

Cada criança foi individualmente entrevistada em duas sessões com intervalo de sete a nove dias entre elas. Na primeira sessão era realizado um Teste de Memória Verbal e a Tarefa de Produção; na segunda sessão, era aplicada a Tarefa de Compreensão. A produção antecedia a compreensão 
para evitar que o conteúdo da história ouvida na tarefa de compreensão influenciasse a produção da história. As sessões foram gravadas e transcritas literalmente, sendo registrado todo o comportamento não-verbal da criança.

\section{Teste de Memória Verbal}

Elaborado por Jorm, Share, Macclean e Matthews (1984), o teste consistia na apresentação de 12 sentenças que aumentavam de tamanho no decorrer da aplicação ${ }^{1}$. Duas sentenças iniciais serviam de treino, sendo corrigidas pelo examinador quando incorretamente respondidas. As sentenças eram lidas uma a uma, após o que solicitava-se da criança a repetição da sentença exatamente como a ouvira. A justificativa para a inclusão deste teste é que a memória a curto prazo, avaliada através de um teste de memória verbal, é fator que pode influenciar o desempenho na compreensão de textos ${ }^{2}$.

\section{Tarefa de Produção de História}

Solicitava-se a elaboração de uma história a partir de um tema fornecido: "Uma flor que vivia triste num jardim". O fornecimento do tema teve por objetivos: (a) restringir o tipo de conhecimento que a criança deveria utilizar durante a criação do texto; (b) favorecer, através da personificação da flor, a entrada da criança no mundo da fantasia, sugerindo, assim, o frame adequado ao gênero narrativo investigado; (c) indicar um estado inicial que necessitava ser mudado, sugerindo-se uma meta a ser alcançada pelo personagem principal.

\section{Tarefa de Compreensão de História}

À criança era dito que, após ouvir uma história no gravador (Apêndice A), deveria recontar a história ouvida ${ }^{3}$. O objetivo era investigar a compreensão a partir da reprodução de uma história ouvida. Considera-se que a paráfrase da história envolve a reorganização da cadeia causal que estrutura o texto e a transformação desse conhecimento em um todo significativo e coerente. Desse modo, não era esperada uma reprodução literal, mas um texto em que as principais idéias da história ouvida fossem preservadas.

O tema da história apresentada na tarefa de compreensão era o mesmo proposto na tarefa de produção, neutralizando a possível influência que a maior ou menor familiaridade com um determinado tópico poderia provocar no desempenho. A história foi elaborada seguindo o modelo definido pela Gramática de História (Stein, 1988; Stein \& Glenn, 1979).

\section{Análise dos dados}

\section{A produção de histórias}

Para a análise das produções foram elaboradas categorias de organização textual, enfatizando-se as relações entre os enunciados, e as relações entre a história criada pela cri- ança e o tema. Essas categorias tiveram por base o sistema de análise originalmente proposto por Rego (1986) e adaptado por Spinillo (1993, 1996; Spinillo \& Pinto,1994). Cada história produzida foi classificada em uma das cinco categorias de produção descritas na Tabela 1, sendo analisadas por dois juizes independentes, cujo percentual de concordância foi de $85 \%$. As discordâncias foram analisadas por um terceiro juiz, também independente, cujo julgamento foi considerado final.

\section{A compreensão de história}

As categorias adotadas na análise das reproduções seguiram o mesmo princípio das categorias da produção. A principal diferença entre elas foi que se analisou o texto reproduzido em relação à proximidade e fidelidade que este apresentava com a história original ouvida no gravador e em relação à presença das principais inferências necessárias à compreensão do texto ${ }^{4}$. O sistema de categorias adotado procurou integrar tanto a produção textual (visto que a reprodução envolve a produção de um texto), como a proximidade e fidelidade ao texto original (visto que a reprodução envolve a produção de um texto em particular e não de qualquer texto).

O texto apresentado foi dividido em cinco blocos de conteúdos, como feito por Marcuschi (1989). Os blocos podem ser assim descritos:

Bloco 1 - apresentação do problema da flor: flor triste porque não tem amigos.

Bloco 2 - encontro da flor com o passarinho e sua decisão em ajudá-la.

Bloco 3 - ação empreendida pelo passarinho para ajudar a flor: passarinho planta sementes ao lado da flor, enquanto ela dorme.

Bloco 4 - resultado da ação empreendida pelo passarinho: chove e as sementes brotam.

Bloco 5 - conclusão, desfecho: flor feliz com suas amigas.

As categorias de análise das reproduções, apresentadas na Tabela 1, refletem tanto o número de blocos reproduzidos, como a maneira como estes se articulam entre si na reconstituição da história. As reproduções foram classificadas por dois juizes independentes, da mesma forma que o foram as produções. Verificou-se um percentual de $83,3 \%$ de concordância entre os juizes.

\section{Teste de Memória Verbal}

A pontuação (máximo de 12 pontos) foi dada em função do número de frases corretamente repetidas. Eram considerados erros a inserção, omissão ou troca de palavras, mesmo que por palavras sinônimas. Para efeito de análise 
Tabela 1

Categorias de produção e de compreensão

\begin{tabular}{|c|c|c|}
\hline Categoria & Produção & Compreensão \\
\hline I & $\begin{array}{l}\text { Produções que são a mera repetição do } \\
\text { tema proposto; ou a produção de frases } \\
\text { desconectadas que podem ou não estar } \\
\text { relacionadas ao tema. }\end{array}$ & $\begin{array}{l}\text { Reproduções desconectadas de anedotas } \\
\text { ou histórias diferentes daquela ouvida, } \\
\text { ou narrativas que limitam-se a frases que } \\
\text { marcam a abertura e fechamento de } \\
\text { histórias. }\end{array}$ \\
\hline II & $\begin{array}{l}\text { Produções que apenas descrevem estados } \\
\text { de personagens ou eventos em uma } \\
\text { sequiência temporal de ações sem que } \\
\text { sejam explicitadas relaçôes causais entre } \\
\text { os enunciados. O tema serve apenas para } \\
\text { inserir os enunciados em um mesmo } \\
\text { tópico e para sugerir o personagem } \\
\text { principal. }\end{array}$ & $\begin{array}{l}\text { Reproduções que, embora envolvam } \\
\text { alguns personagens e alguns eventos } \\
\text { presentes em determinados blocos da } \\
\text { história original incluem acréscimos ou } \\
\text { redefinição de informações pouco fiel a } \\
\text { história original. }\end{array}$ \\
\hline III & $\begin{array}{l}\text { Produções que se caracterizam por uma } \\
\text { sequiência de eventos interligados por } \\
\text { relações causais. O tema abre ou fecha a } \\
\text { história, servindo como eixo norteador. } \\
\text { Algumas histórias descrevem tentativas de } \\
\text { incluir uma meta/motivo para o } \\
\text { personagem principal. }\end{array}$ & $\begin{array}{l}\text { Reproduções que se limitam a eventos } \\
\text { de alguns blocos, em particular o Bloco } \\
2 \text { (encontro da flor com o passarinho) e } \\
\text { o Bloco } 3 \text { (ação do passarinho para } \\
\text { ajudar a flor). Isto é feito de forma } \\
\text { desarticulada, estando ausentes as } \\
\text { cadeias causais relevantes. Além das } \\
\text { omissões, há acréscimos ou redefinição } \\
\text { de informações pouco fiel a história } \\
\text { original. }\end{array}$ \\
\hline IV & $\begin{array}{l}\text { Produções que apresentam uma situação } \\
\text { problema a ser resolvida pelo personagem } \\
\text { principal e que o motiva. Apresentam um } \\
\text { desfecho que modifica o estado inicial do } \\
\text { personagem. Este desfecho é repentino e } \\
\text { pouco elaborado, sem haver uma conexão } \\
\text { precisa entre o problema e a sua } \\
\text { resolução. }\end{array}$ & $\begin{array}{l}\text { Reproduções globais com certa } \\
\text { articulação, porém incompletas. } \\
\text { Referência ao problema central (Bloco } \\
\text { 1) e ao desfecho (Bloco 5). Omissões e } \\
\text { trocas de informações. A cadeia causal } \\
\text { não é totalmente reproduzida. O Bloco } 3 \\
\text { (ação do passarinho para ajudar a flor) e } \\
\text { o Bloco } 4 \text { (resultado de sua ação) podem } \\
\text { estar omitidos. Quando presentes, as } \\
\text { relações causais entre eles são omitidas. }\end{array}$ \\
\hline V & $\begin{array}{l}\text { Trama mais complexa, podendo surgir } \\
\text { novos personagens e problemas além } \\
\text { daquele sugerido pelo tema. Maior } \\
\text { elaboração na passagem do estado inicial } \\
\text { para o estado final, explicitando-se os } \\
\text { meios de resolução da situação-problema. }\end{array}$ & $\begin{array}{l}\text { Reprodução completa, em que as idéias } \\
\text { centrais e as inferências* são } \\
\text { reproduzidas de maneira articulada. A } \\
\text { narrativa segue um eixo onde o } \\
\text { problema é apresentado e resolvido, } \\
\text { reproduzido-se os meios para tal. As } \\
\text { relações causais importantes estão } \\
\text { presentes. }\end{array}$ \\
\hline
\end{tabular}

*As histórias reproduzidas apresentavam, pelo menos, duas das inferências essenciais presentes no texto original.

descritiva multidimensional, (Análise fatorial do tipo Análise de Correspondências, técnica formalizada no programa ADDAD. ANCOR ()), foram formados quatro grupos a partir do desvio padrão (2.05) da distribuição dos dados referentes à freqüência de acertos das crianças neste teste. Assim, o número de sentenças corretamente reproduzidas foi agrupado da seguinte maneira: de 3-5 sentenças (MEM1); de 6-7 sentenças (MEM2); de 8-9 sentenças (MEM3) e de 10-12 sentenças (MEM4). A Análise de Correspondências gerou uma distribuição e agrupamentos dos dados em um Plano Fatorial que indicava a contribuição da memória na configuração dos dados. De acordo com esta análise, a memória não representou uma variável que contribuísse para a distribuição dos participantes no eixo fatorial, não sendo, portanto, fator determinante do desempenho quer na produção quer na compreensão. Em vista disso, os resultados referentes a este teste não são considerados na análise inferencial. 
Exemplos das histórias em cada uma das categorias são apresentadas a seguir. Exemplos de histórias na Tarefa de Produção:

Categoria I - "A flor chorou muito. Ela tava muito triste."

Categoria II - " Choveu muito na florzinha. Aí parou, parou a chuva, ficou de sol. Ela dormiu. Quando chegou amanhã ela foi brincar."

Categoria III - " Uma florzinha muito pequena vivia num jarrinho muito triste, sem conversar, sem brincar, sem conversar, sem ver os amigos, sem ver os pais, sem ver nada! Ficava chorando no jarrinho dela,. Não ganhava água, não ganhava presente, não fazia compras. Não fazia nada, só ficava no jarrinho dela triste chorando, porque não tinha pais, não tinha ninguém pra ficar com ela. “

Categoria IV - " Era uma vez uma florzinha muito bonitinha, mas ela é uma chorona. Aí, quando um menino ía passando, arrancou ela sem ela saber. Ela chorava. Aí ele jogou ela. Aí ela morreu porque ele não botou água. Aí ela chorou que tava com sede. Aí Deus, foi e fez ela de novo. Aí foi feliz para sempre."

Categoria V - "Era uma vez uma flor que vivia no jardim. Sempre era regada, mas nunca gostava de ser regada porque regavam ela sem amor. Um dia ela conheceu mais duas rosas que foram plantadas junto dela. E elas conversavam todo dia. As outras duas rosas eram regadas com muito amor e ela não. Todos os dias ela pensava: "Por que eu não sou regada com amor?" Ficava pensando, pensando e as outra pessoas ficavam conversando. Um dia ela conversou muito, o dia todo com as rosas, e perguntou: "Por que vocês são regadas com amor e eu não?" "- Porque você tem muito espinho e fura muito as pessoas e nós não." E ela disse: "Então vou tentar não furar mais as pessoas." Então passaram o tempo e ela demorou a furar as pessoas, parou de furar as pessoas. $E$ as pessoas regavam ela com muito amor. E ela ficou alegre no jardim.”

Exemplos de histórias reproduzidas na Tarefa de Compreensão:

Categoria I - "A flor que vivia triste, que ela viveu feliz."
Categoria II - "Era uma vez uma florzinha que morava num jardim. Um dia ela encontrou as árvores. $E$ as árvores começavam a falar com ela. Por enquanto que a flor dormia a árvore regou as plantas. E quando ela acordou disse: que surpresa!"

Categoria III - "O passarinho ele foi no outro quintal e achou um bocado de sementinha com o bico e botou pra ela. Quando amanheceu, choveu muito de noite. Quando amanheceu, ela teve uma linda surpresa, um bocado de florzinha para conversar o dia inteiro."

Categoria IV - "Era uma vez uma flor que morava numa floresta cheia de árvores bem grande. As árvores grande não gostavam delas. Um dia, veio um passarinho e a flor e a flor resolveu conversar com o passarinho. Ela contou ao passarinho que ela estava muito triste, que não tinha amigos. Aí uma vez, ela ficou com muitos amigos."

Categoria V -"Era uma vez uma flor que morava no jardim que não tinha nenhuma amiga, porque só tinha árvore no jardim. Um dia um passarinho veio no jardim e perguntou: - Por que você está tão triste? Ela respondeu: - É porque eu aqui eu não tenho nenhuma amiga. $\mathrm{O}$ passarinho, tentando ajudar, foi no quintal vizinho, pegou um monte de sementes de flores. Ao amanhecer, ao anoitecer, os passarinhos, o passarinho plantou todas as sementes na terra perto da flor. No, nessa noite choveu muito e no dia seguinte as flores estavam já estavam em pé. Aí aquela florzinha viveu feliz para sempre."

"Era uma vez uma flor que vivia solitária num quintal cheio de árvores. Árvores grandes que não gostavam dela. Ai um dia um passarinho chegou. Ela contou tudo para ele. Que não tinha ninguém para brincar, conversar. Ele teve uma idéia de plantar sementes de flores para ela. Ai ele voou para um outro quintal e pegou sementes de flores. De noite, quando a florzinha estava dormindo, o passarinho plantou as sementes de todas as flores. Ai choveu, choveu e isso fez as flores crescer logo. Quando a florzinha levantou ... acordou, ela teve a surpresa. Foi surpresa porque ela não sabia que ele tinha plantado e ai viu todas as flores. Ela ficou feliz com suas amiguinhas as flores. A flor ficou feliz para sempre."

Tabela 2

Porcentagem em cada Categoria por Idade na Tarefa de Produção

\begin{tabular}{cccc}
\hline Categorias & 4 anos & 6 anos & 8 anos \\
\hline I & 40 & 10 & 5 \\
II & 25 & 30 & 10 \\
III & 20 & 30 & 20 \\
IV & 15 & 30 & 20 \\
V & 0 & 0 & 45 \\
\hline
\end{tabular}


Tabela 2

Porcentagem em cada Categoria por Idade na Tarefa de Compreensão

\begin{tabular}{cccc}
\hline Categoria & 4 anos & 6 anos & 8 anos \\
\hline I & 65 & 5 & 5 \\
II & 15 & 15 & 0 \\
III & 15 & 30 & 5 \\
IV & 5 & 20 & 30 \\
V & 0 & 30 & 60 \\
\hline
\end{tabular}

\section{Resultados e discussão}

\section{O desempenho na tarefa de produção}

A Tabela 2 apresenta a porcentagem das produções classificadas em cada categoria em função da idade.

O Teste U de Mann-Whitney revelou diferenças significativas entre as idades ( 4 anos vs. 6 anos: $\mathrm{p}<.05 ; 4$ anos $v s$. 8 anos: p<.001; e 6 anos vs. 8 anos: p<.01). As produções aos 4 anos são mais elementares do que nas demais faixas etárias; enquanto aos 8 anos as produções são mais elaboradas. Aos 4 anos as histórias concentram-se na Categoria I (40\%), enquanto aos 6 anos observa-se um baixo percentual de produções na Categoria I (10\%) e uma distribuição equivalente nas Categorias II, III e IV (30\%). As crianças de 4 e 6 anos não produzem histórias na Categoria V. Em contraste, aos 8 anos, as histórias concentram-se na Categoria V (45\%), sendo raras aquelas classificadas nas Categorias I (5\%) e II (10\%). Embora os três grupos de idade se diferenciem significativamente quanto à organização textual das produções, o padrão de resultados das crianças de 6 anos parece estar mais próximo das crianças de 4 anos do que das crianças de 8 anos.

\section{O desempenho na tarefa de compreensão}

A Tabela 3 apresenta as porcentagens de reproduções em cada categoria por idade.

O Teste U de Mann-Whitney identificou variações significativas entre os três grupos etários (4 anos vs. 6 anos, $\mathrm{p}<.001 ; 4$ anos $v s .8$ anos: $\mathrm{p}<.001 ; 6$ anos $v s .8$ anos: $\mathrm{p}<.05)$. Novamente, como ocorreu com a produção de histórias, as crianças de 4 anos apresentam um nível de desempenho mais elementar que as demais idades, enquanto as de 8 anos apresentam reproduções mais elaboradas que as crianças dos outros dois grupos. Como mostra a Tabela 3, a maioria das reproduções aos 4 anos se concentra na Categoria I (65\%), sendo raras aquelas classificadas na Categoria IV (5\%), estando ausentes reproduções na Categoria V. Aos 6 anos notase uma distribuição equilibrada entre as Categorias III, IV e V (30\%, 20\% e 30\% respectivamente). As crianças de 8 anos apresentam uma grande concentração de reproduções na Categoria V (60\%). Apesar dos três grupos se diferenciarem significativamente quanto à qualidade das reproduções feitas, as crianças de 6 anos apresentam um padrão de resultados mais próximo das crianças de 8 anos do que das crian-

Tabela 4

Porcentagem de Crianças nas Categorias de Produção e de Compreensão

\begin{tabular}{ccc}
\hline & Produção & Compreensão \\
\hline I & 18 & 25 \\
II & 22 & 10 \\
III & 23 & 17 \\
IV & 22 & 18 \\
V & 15 & 30
\end{tabular}


ças de 4 anos. Este dado difere daquele observado em relação à produção.

\section{Comparações e correlações entre produção e compreensão de textos}

O Teste Wilcoxon examinou se haveria diferenças significativas entre produção e compreensão na amostra em geral e em cada idade separadamente. Considerando-se a amostra como um todo, identificaram-se diferenças significativas entre produção e compreensão $(\mathrm{p}<.05)$.

A principal diferença entre as tarefas é que $30 \%$ das crianças alcançam a Categoria $V$ na compreensão, enquanto que apenas $15 \%$ delas o fazem na produção. Há, portanto, um maior percentual de crianças que apresentam níveis de compreensão mais sofisticados do que níveis de produção. Este resultado sugere que, na faixa etária investigada, as crianças são mais bem sucedidas na compreensão do que na produção. Entretanto, este padrão geral de resultados não se repete em cada idade. Considerando cada idade separadamente, observam-se diferenças significativas entre produção e compreensão em todas as idades: 4 anos ( $p<.05) ; 6$ anos $(\mathrm{p}<.01)$ e 8 anos $(\mathrm{p}<.05)$.

Comparando-se os resultados nas Tabelas 2 e 3, é possível verificar que aos 4 anos as crianças produzem melhor do que compreendem, visto que $15 \%$ das histórias estão na Categoria IV na produção e apenas $5 \%$ na Categoria IV na compreensão. Na produção, $40 \%$ estão na Categoria I e na compreensão 65\% na Categoria I. Aos 6 e 8 anos, observase o oposto: as crianças compreendem melhor do que produzem, pois na compreensão alcançam mais freqüentemente a Categoria V (30\% aos 6 anos e $60 \%$ aos 8 anos), enquanto na produção esses percentuais são mais baixos $(0 \%$ aos 6 anos e $45 \%$ aos 8 anos).

O Teste Tau de Kendall examinou as possíveis correlações entre produção e compreensão. $\mathrm{O}$ cruzamento entre as duas tarefas é apresentado na Tabela 5.

Não se identificou correlação significativa entre produção e compreensão quer no geral, quer em cada idade separadamente. Este resultado contrasta com aquele obtido por Cain e Oakhill (1996), e está em acordo com o que foi observado por Gutman \& Fredericksen (1985).

Apesar da inexistência de correlação significativa, notase que há certas tendências em relação às idades de 4 e 8 anos que merecem ser comentadas. Note-se que, aos 4 anos, $60 \%$ das crianças (12 em 20) compreendem e produzem histórias nas categorias mais elementares (I e II); enquanto que aos 8 anos, 65\% das crianças (13 em 20) apresentam compreensão e produção em categorias elaboradas (IV e V). Embora não haja uma correlação significativa, nota-se uma tendência à associação, na medida em que a produção e compreensão concentram-se em categorias elementares aos 4 anos, e aos 8 anos em categorias elaboradas. Aos 6 anos o desempenho nas duas tarefas revela-se bastante diversificado, sendo a não-correlação mais evidente do que nas demais idades.

\section{Comentários finais e conclusões}

Produção e compreensão de textos são habilidades que se desenvolvem entre as idades de 4 a 8 anos. Na produção, este desenvolvimento é mais acentuado após os 6 anos; en-

Tabela 5

Número de Crianças nas Categorias de Produção e de Compreensão

\begin{tabular}{cccccc}
\hline \multicolumn{7}{c}{ Compreensão } \\
\hline Produção & Cat. I & Cat. II & Cat. III & Cat. IV & Cat. V \\
\hline Cat. I & 6 & 1 & 1 & 0 & 0 \\
Cat. II & 3 & 2 & 0 & 0 & 0 \\
Cat. III & 3 & 0 & 1 & 0 & 0 \\
Cat. IV & 1 & 0 & 1 & 1 & 0 \\
Cat. V & 0 & 0 & 0 & 0 & 0 \\
\hline & & & 6 anos & & 1 \\
\hline Cat. I & 1 & 0 & 0 & 0 & 2 \\
Cat. II & 0 & 1 & 2 & 2 & 1 \\
Cat.III & 0 & 1 & 2 & 1 & 2 \\
Cat. IV & 0 & 1 & 0 & 0 & 0 \\
Cat. V & 0 & 0 & 0 & 0 & 0 \\
\hline Cat. I & 1 & 0 & 0 & 0 & 2 \\
Cat. II & 0 & 0 & 1 & 1 & 2 \\
Cat.III & 0 & 0 & 0 & 2 & 6 \\
Cat. IV & 0 & 0 & 0 & 3 & 2 \\
Cat. V & 0 & 0 & 0 anos & \\
\hline
\end{tabular}


quanto na compreensão, o desenvolvimento é mais acentuado antes dos 6 anos. Isto sugere que a idade de 6 anos é momento crucial no desenvolvimento dessas habilidades.

Analisando-se as relações entre produção e compreensão de textos, objetivo principal desta investigação, verificase que a hipótese de que tais habilidades inicialmente não se correlacionariam, mas que, com o desenvolvimento, tenderiam a uma correlação, não se confirmou. Quer na amostra como um todo, quer em cada idade isoladamente, não se observa uma correlação significativa entre produzir e compreender histórias. Este resultado confirma os dados de Guttman e Frederiksen (1985) e vão de encontro àqueles obtidos por Cain e Oakhill (1996). É difícil explicar a divergência entre os resultados. Talvez esta diferença seja conseqüência do fato de que naquela investigação a tarefa de compreensão envolvia responder perguntas, enquanto no presente estudo a tarefa envolvia a reprodução de um texto ouvido. Importante mencionar que tanto o presente estudo como o de Guttman e Frederiksen (1985) não encontraram correlação entre produção e compreensão, e que nesses estudos adotou-se a reprodução para avaliar a compreensão. Para examinar de forma apropriada esta possibilidade, seria necessário planejar um estudo que envolvesse a produção de histórias e os dois tipos de tarefa de compreensão: reprodução e perguntas.

O dado mais interessante é que as relações entre produção e compreensão não são as mesmas ao longo do desenvolvimento. Em outras palavras, o desenvolvimento altera a maneira como essas habilidades se relacionam. Enquanto aos 4 anos as crianças apresentam níveis de produção mais sofisticados do que na compreensão; aos 6 e 8 anos ocorre o inverso: as crianças compreendem melhor do que produzem. Quais as razões para um resultado desta natureza? Por que aos 4 anos é mais fácil produzir do que compreender?

Para responder a estas questões é necessário retomar a discussão conduzida por Brandão e Spinillo (1998), a respeito do fato de que tarefas distintas avaliam aspectos distintos da compreensão, e que reproduzir um texto envolve esforços lingüísticos e cognitivos mais complexos do que responder perguntas. Talvez a tarefa de compreensão (reprodução) tenha sido difícil para as crianças de 4 anos, embora não tenha sido para as de 6 e 8 anos. As dificuldades com a reprodução parecem residir no fato de que as crianças de 4 anos não conseguem ater-se ao texto apresentado enquanto o reproduzem, e não integram simultaneamente o processo de manter o texto original em mente e a produção que estão realizando. Por outro lado ${ }^{5}$, as crianças de 6 e de 8 anos lidam simultaneamente com essas duas instâncias sem demonstrar dificuldades. Na realidade, a reprodução de textos requer estabelecer dois níveis de relações: uma entre textos (texto que está sendo produzido e o texto original) e ou- tra intra-texto (relações entre os enunciados do texto que está sendo produzido). Em outras palavras, enquanto para as crianças de 6 e 8 anos o texto ouvido serve de apoio, para as crianças de 4 anos ele serve apenas como um elemento gerador de um tema para a produção de uma nova história.

Para finalizar, conclui-se que, dependendo da idade, as relações entre compreensão e produção se alteram. Entre as crianças mais jovens, é mais fácil produzir um texto original do que expressar a compreensão através da reprodução de um texto ouvido. Com a idade, esta relação se inverte, sendo mais fácil expressar a compreensão através da reprodução do que produzir um texto original. Este desenvolvimento sugere formas distintas em lidar com textos que servem de modelo para a reprodução: enquanto crianças pequenas não usufruem deste modelo em suas produções, crianças mais velhas o fazem, apresentando melhoras significativas na atividade de recontar como sugerido por Lins e Silva e Spinillo (2000) e Merrit e Liles (1989).

\section{Agradecimentos}

O artigo faz parte da Dissertação de Mestrado da primeira autora, sob a orientação da segunda, na Pós-Graduação em Psicologia da UFPE. As autoras agradecem o apoio do CNPq sob forma de bolsa de estudos conferida à primeira autora; e, em especial, a Jane Oakhill (Unversity of Sussex) e Luis Antonio Marcuschi (UFPE) pelos comentários que contribuiram de forma substancial na elaboração deste estudo.

\section{Referências}

Berman, R. A., \& Slobin, D. I. (1994). Introduction. In R. A. Berman, \& D. I. Slobin (Orgs.), Relating events in narrative: a crosslinguistic developmental study (pp. 1-38). Hillsdale: Lawrence Erlbaum Associates.

Brandão, A .C. P., \& Spinillo, A . G. (1998). Aspectos gerais e específicos na compreensão de textos. Psicologia: Reflexão e Crítica, 11(2), 253-272.

Cain, K., \& Oakhill, J. (1996). The nature of the relationship between comprehension skill and the ability to tell a story. British Journal of Developmental Psychology, 14, 187-201.

Guttman, M., \& Frederiksen, C. H. (1985). Preschool children's narratives: linking story comprehension, production and play discourse. In L. Galda, \& A. D. Pellegrini (Orgs.), Play, language and stories: the development of children's literate behavior (pp. 69-92). Norwood: Ablex.

Graesser, A. C. \& Britton, B. K. (1996). Five metaphors for text understanding. In Britton, B. K. \& Graesser, A. C. (Orgs.), Models of understanding text (pp. 341-351). Mahwah: Lawrence Erlbaum Associates.

Hudson, J. A., \& Shapiro, L. R. (1991). From knowing to telling: The development of children's scripts, stories, and personal narratives. In A. McCabe, \& C. Peterson (Orgs.), Developing Narrative Structure (pp. 89-136). Hillsdale: Lawrence Erlbaum Associates.

Jorm, A., Share, D., Maclean, R., \& Matthews, R. (1984). Phonological confusability in short-term memory for sentences as a predictor of reading ability. British Journal of Psychology, 75, 393-400.

Just, M. A., \& Carpenter, P. A. (1992). A capacity theory of comprehension. Individual differences in working memory. Psychological Review, 99, 122-149. 
Kintsch, W. (1998). Comprehension: A paradigm for cognition. Cambridge: University Press.

Lins e Silva, M. E. (1994). O desenvolvimento de escrita de histórias. Dissertação de mestrado não-publicada, Universidade Federal de Pernambuco, PE, Brasil.

Lins e Silva, M. E., \& Spinillo, A. G. (2000). A influência de diferentes situações de produção na escrita de histórias. Psicologia: Reflexão e Crítica, 13, 337350

Marcuschi, L. A. (1989). O processo inferencial na compreensão de textos. Relatório Técnico-Científico (CNPq).

Merrit, D. D., \& Liles, B. Z.(1989). Narrative analysis: clinical applications of story generation and story retelling. Journal of Speech and Hearing Disorders, 54, 429-438.

Oakhill, J., \& Yuill, N. (1996). Higher order factors in comprehension disability: processes and remediation. In C. Cornoldi, \& J. Oakhil (Orgs.), Reading comprehension difficulties: processes and intervention (pp. 69-92). Mahwah: Lawrence Earlbaum Associates.

Perfetti, C. A., Marron, M. A., \& Foltz, P. W. (1996) Sources of comprehension failure: Theoretical perspective and case studies. In C. Cornoldi, \& J. Oakhill (Orgs.), Reading comprehension difficulties: processes and intervention (pp. 137-165). Mahwah: Lawrence Earlbaum Associates.

Rego, L. L. B. (1986). A escrita de estórias por crianças: as implicações pedagógicas do uso de um registro lingüístico. Revista de Documentação de Estudos em Lingüística Teórica e Aplicada, 2, 165-180.

Rego, L. L. B. (1989). A evolução da concepção de história na criança em três habilidades distintas: memória, criação e julgamento. Manuscrito não-publicado.
Shapiro, R. L., \& Hudson, J. A (1997). Coherence and cohesion in children's stories. In J. Costermans, \& M. Fayol (Orgs.), Processing interclausal relationships: Studies in the production and comprehension of text (pp. 23-48). Mahwah: Lawrence Erlbaum Associates.

Spinillo, A. G. (1993). Era uma vez ... e foram felizes para sempre. Esquema narrativo e variações experimentais. Temas em Psicologia. Desenvolvimento Cognitivo: Linguagem e Aprendizagem, 1, pp. 67-78.

Spinillo, A. G. (1996). O uso de coesivos por crianças com diferentes níveis de domínio de um esquema narrativo. In M. G. B. B. Dias, \& A. G. Spinillo (Orgs.), Tópicos em Psicologia Cognitiva (pp 84-119). Recife: Editora Universitária da UFPE.

Spinillo, A. G., \& Pinto, G. (1994). Children's narratives under different conditions: a comparative study. British Journal of Developmental Psychology, 12, 177-193.

Spinillo, A. G., \& Martins, R. A . (1997). Uma análise da produção de histórias coerentes por crianças. Psicologia: Reflexão e Crítica, 10, 219-248.

Stein, N. L. (1988). The development of children's storytelling skill. In M. B. Franklin, \& S. Barten (Orgs.), Child Language: a book of readings (pp. 228-297). Oxford: Oxford University Press.

Stein, N. L., \& Glenn, C. G. (1979). An analysis of story comprehension in elementary school children. In R. O. Freedle (Org.), New directions in discourse processing. Advances in discourse processes (Vol. 2, pp. 53-120). Norwood: Ablex.

Takahashi, N. (1992). Developmental changes of young children's story comprehension. Trabalho apresentado no 25th International Congress of Psychology, Bruxelas, Bélgica.

Yuill, N., \& Oakhill, J. (1991). Children's problems in text comprehension: an experimental investigation. Cambridge: Cambridge University Press.

\section{Notas}

1 Embora não padronizado para o Brasil, este teste foi traduzido e utilizado em diversos estudos com crianças brasileiras (e.g. Rego, 1989; Lins e Silva, 1994.)

2 A importância da memória na compreensão de textos é ressaltada tanto nos modelos teóricos sobre o tema (e.g. Graesser \& Britton, 1996; Kintsch, 1998) como através de evidências empíricas (e.g. Just \& Carpenter, 1992; Oalhill \& Yuill, 1996; Perfetti, Marron \& Foltz, 1996; Yuill \& Oakhill, 1991).

3 A opção pela gravação da história ao invés da leitura pelo examinador objetivou eliminar possíveis interferências tais como: variação de ritmo e velocidade de leitura, entoação e tom de voz.

4 As inferências à compreensão da história eram: as amigas eram as flores, as flores tinham crescido por causa da chuva, a idéia que teve o passarinho, a surpresa da flor.

5 Estes resultados não podem ser entendidos como decorrentes de limites na memória, devido à ausência de relação entre desempenho e memória de curto termo tanto na produção como na compreensão.

Ana Carolina Perusi Brandão, mestre em Psicologia pela Pós-Graduação em Psicologia da UFPE, atualmente realizando estudos de doutorado na University of Sussex, Inglaterra, é Professora Assistente do Centro de Educação da Universidade Federal de Pernambuco.

Alina Galvão Spinillo, doutora em Psicologia do Desenvolvimento pela University of Oxford, Inglaterra, com Pós-Doutorado na University of Sussex, Inglaterra, é Professora Adjunta do Departamento de Psicologia da Universidade Federal de Pernambuco, docente e pesquisadora na Pós-Graduação em Psicologia desta universidade.

Endereço para correspondência: Alina Galvão Spinillo, Universidade Federal de Pernambuco, PósGraduação em Psicologia, CFCH $8^{\circ}$ andar, Cidade Universitária, 50.670-901 Recife, PE. Fone:

(81)271-8272; Fax: (81)271-1843. Email: spin@npd.ufpe.br. 


\section{Apêndice A: História apresentada na Tarefa de Compreensão}

Era uma vez uma flor que morava num quintal cheio de árvores grandes. A flor vivia muito triste pois não havia ninguém com quem pudesse conversar. As árvores grandes não gostavam dela e nunca a convidavam para brincar.

Um dia, a flor viu um passarinho e resolveu conversar com ele. Ela foi logo dizendo que estava muito triste e sozinha.

- Por que você está tão triste? perguntou o passarinho.

- Aqui fico muito sozinha, disse a flor. Não tenho amigos. Você poderia ajudar?

- Não se preocupe, respondeu o passarinho, tenho uma idéia para acabar com sua tristeza. E lá foi ele voando rápido para um jardim vizinho.

Neste jardim o passarinho apanhou com o bico, várias sementes de flores. A noite, voltou para o quintal onde a florzinha morava e enquanto ela dormia, plantou as sementes na terra.

Naquela noite, choveu muito. Ao amanhecer, a flor teve uma grande surpresa. O quintal parecia um lindo jardim!

Desde então, a flor viveu muito feliz, pois agora tinha muitas amigas para conversar. 